\title{
Direitos reprodutivos, aborto e Serviço Social
}

\author{
Reproductive Rights, Abortion And Social Work
}

\author{
Cássia Maria Carloto \\ Doutora em Serviço Social pela PUC-SP, docente do Departamento de \\ Serviço Social da Universidade Estadual de Londrina, PR, Brasil. cmcarloto@gmail.com.
}

Nayara André Damião

Assistente social, mestranda do Programa de Pós-Graduação em Serviço Social e Política Social da Universidade Estadual de Londrina, PR, Brasil. nayara.damiao@gmail.com

\begin{abstract}
RESUMO: Os direitos reprodutivos foram demarcados, pelo movimento feminista, como parte dos direitos humanos das mulheres. O aborto é um dos direitos contemplados pela concepção de direitos reprodutivos, tendo como argumento central a autonomia das mulheres sobre o próprio corpo. O Serviço Social, que é uma profissão atrelada à garantia de direitos, tem se manifestado nesse debate, por meio do CFESS e enfrentando a reação de setores conservadores que buscam retroceder em direitos já conquistados. É sobre direitos reprodutivos, o aborto no Brasil e o Serviço Social que tratará este artigo.
\end{abstract}

Palavras-chave: Direitos reprodutivos. Aborto. Serviço Social. Feminismo.
ABSTRACT: Reproductive rights were established by feminism, as part of human rights. Abortion is one of the rights assumed by the notion of reproductive rights, having as central argument women autonomy with their own bodies. Social work, a profesion related to rights guarantee, has manifested, through its Council, against conservative reactions which aims regressions in rights. Reproductive rights, abortion in Brazil and Social Work are the subjects discussed in this article.

Keywords: Reproductive Rights. Abortion. Social Work. Feminism.

\section{Introdução}

Não foi coincidência o fato de que a consciência das mulheres sobre seus direitos reprodutivos tenha nascido no interior do movimento organizado em defesa da igualdade política das mulheres. Na verdade, se elas permanecessem para sempre sobrecarregadas por incessantes partos e frequentes abortos 
espontâneos, dificilmente conseguiriam exercitar os direitos políticos que poderiam vir a conquistar. (Angela Davis, 2016)

negação do direito das mulheres à autonomia sobre o próprio corpo
reflete uma estrutura patriarcal, apropriada pelo capitalismo, sobre
a qual as relações sociais se constroem. O patriarcado, segundo Saffioti (2004), organiza um sistema de dominação e exploração que oprime as mulheres, explorando seu trabalho e corpo para assegurar a produção e reprodução da vida. A sexualidade e reprodução da mulher são pontos-chave para a dominação e a exploração das mulheres. Como afirma Saffioti (2004), patriarcado, racismo e capitalismo formam um só sistema, que estrutura as relações sociais de maneira consubstancial. ${ }^{1}$ Por isso, as condições em que as mulheres podem fazer escolhas sobre sua autonomia reprodutiva e garantia e exercício de direitos reprodutivos são dadas por essas três dimensões. O aborto é parte desse debate.

O Serviço Social é uma profissão que lida com a garantia de direitos. Nesse sentido, se analisarmos o aborto como um direito - conforme os dispositivos internacionais têm tratado - , enxergamos no Serviço Social uma área para essas reflexões e atuação acerca dos direitos reprodutivos das mulheres. Nesse contexto, o Conselho Federal de Serviço Social (CFESS) já se manifestou a favor da luta pela legalização do aborto. Diversas comunicações oficiais tratando do tema foram publicadas, e o debate sobre o aborto vem sendo aquecido pelo órgão federal e por suas regionais com os profissionais da área.

No entanto, ainda prevalece uma lacuna no enfrentamento desse assunto na produção acadêmica e na formação dos e das assistentes sociais que no cotidiano de trabalho se deparam com mulheres, nossa principal população atendida.

1. Segundo Kergoat (2010, p. 94), as relações sociais são consubstanciais, "formam um nó que não pode ser desatado no nível das práticas sociais, mas apenas na perspectiva da análise sociológica" e coextensivas; "ao se desenvolverem, as relações sociais de classe, gênero e 'raça' se reproduzem e se coproduzem mutuamente". 


\section{Direitos reprodutivos e aborto}

O conceito de direitos reprodutivos se originou dentro do movimento feminista na luta pelo reconhecimento dos direitos da mulher quanto à sexualidade e reprodução, e, posteriormente, também a partir das elaborações dos movimentos de lésbicas e gays. Entretanto, a disputa de sentidos que existe atualmente sobre a temática demarca o envolvimento de outros atores sociais além daqueles anteriores (Ávila, 2003, p. 466).

A perspectiva feminista, adotada aqui, afirma que os direitos reprodutivos

dizem respeito à igualdade e à liberdade na esfera da vida reprodutiva. Os direitos sexuais dizem respeito à igualdade e à liberdade no exercício da sexualidade. $\mathrm{O}$ que significa tratar sexualidade e reprodução como dimensões da cidadania e consequentemente da vida democrática. (Ávila, 2003, p. 466)

Ávila destaca a necessidade de tratar o campo da sexualidade e da reprodução separadamente, para "assegurar a autonomia dessas duas esferas da vida, o que permite relacioná-las entre si e com várias outras dimensões da vida social" (2003, p. 466). A separação entre sexualidade e reprodução possibilita contestar a heterossexualidade compulsória, segundo a qual apenas as relações entre homem e mulher são naturais, relegando à sexualidade feminina a função estritamente reprodutiva.

Os direitos reprodutivos dizem respeito à saúde sexual e reprodutiva; à sobrevivência e à vida; à liberdade e segurança; à não discriminação e respeito às escolhas; à informação e educação para possibilitar decisões; à autodeterminação e livre escolha da maternidade e paternidade; à proteção social à maternidade, paternidade e família (Ventura, 2009, p.19).

Os direitos reprodutivos e sexuais da mulher também foram reconhecidos enquanto parte dos direitos humanos pela Conferência Internacional sobre População e Desenvolvimento (ICPD) do Cairo em 1994, e pela 
$4^{\mathrm{a}}$ Conferência Internacional sobre a Mulher (FWCW) de Beijing, em 1995. A primeira estabeleceu que

\begin{abstract}
Direitos reprodutivos incluem certos direitos humanos que já foram reconhecidos nas leis nacionais, em documentos internacionais sobre direitos humanos e outros documentos de consenso. Esses direitos baseiam-se no reconhecimento dos direitos básicos de todos os casais e indivíduos decidirem livre e responsavelmente o número, espaçamento e momento de terem seus filhos e ter informação e meios para isso, bem como alcançarem o mais alto padrão de saúde sexual e reprodutiva. (Nações Unidas, 1995, parágrafo 7.3)
\end{abstract}

Em Beijing, o acordo foi o seguinte:

Os direitos humanos das mulheres incluem seus direitos a ter controle e a decidir livre e responsavelmente sobre questões relacionadas à sua sexualidade, incluindo saúde sexual e reprodutiva, livres de coerção, discriminação e violência. Relacionamentos igualitários entre mulheres e homens quanto às relações sexuais e reprodutivas, incluindo total respeito à integridade das pessoas, requerem o respeito mútuo, consentimento e compartilhar responsabilidade quanto ao comportamento sexual e suas consequências. (Nações Unidas, 1996, parágrafo 96)

Ressaltamos que o Brasil foi signatário de ambos os dispositivos. Ainda que esses documentos não tenham força de lei, afirmam compromissos com o avanço dos direitos reprodutivos e sexuais. Apesar disso, percebemos que no Brasil a situação relativa aos direitos reprodutivos e sexuais ainda não avançou o suficiente, principalmente quando observamos a permanência da criminalização e a quantidade de mortes de mulheres que recorrem ao aborto. Há inclusive a intenção de retrocesso nos direitos já conquistados.

As leis restritivas acerca do aborto se amparam muitas vezes na religião, um dispositivo de controle das mulheres na ordem patriarcal e que influencia na moralidade do debate relativo ao aborto, contribuindo para a criminalização das mulheres que recorrem a ele. 
Atualmente, apesar da posição contrária da Igreja Católica em relação ao aborto ser hegemônica, ainda há divergências dentro da própria Igreja sobre a questão. Destacamos a posição do Grupo Católicas pelo Direito de Decidir, atuante no Brasil. Com base em argumentos teológicos e pastorais, o grupo busca dar visibilidade a um posicionamento alternativo dentro da Igreja sobre o tema, colocando-se como defensoras do direito de escolha das mulheres.

O aborto é considerado um procedimento de baixa complexidade técnica. O que torna um aborto inseguro é a clandestinidade, "ao favorecer a quebra de alguns daqueles preceitos básicos de segurança” (Mesquita, 2000, p. 37). Esta é a dimensão política da questão. Outra dimensão, a econômica, tem a ver com a seguinte sentença: nem todo aborto clandestino é inseguro, desde que se possa pagar. Há maneiras de realizar o procedimento seguro, mesmo que clandestino. Isso destina às mulheres pobres os maiores níveis de insegurança no que se refere ao aborto.

A Pesquisa Nacional do Aborto (PNA) de 2016, aponta que aproximadamente uma em cada cinco mulheres alfabetizadas da área urbana aos quarenta anos já fez pelo menos um aborto:

É possível observar que o aborto no Brasil é comum e ocorreu com frequência entre mulheres comuns, isto é, foi realizado por mulheres: a) de todas as idades (ou seja, permanece como um evento frequente na vida reprodutiva de mulheres há muitas décadas); b) casadas ou não; c) que são mães hoje; d) de todas as religiões, inclusive as sem religião; e) de todos os níveis educacionais; f) trabalhadoras ou não; g) de todas as classes sociais; h) de todos os grupos raciais; i) em todas as regiões do país; j) em todos os tipos e tamanhos de município. (Diniz, Medeiros e Madeiro, 2017, p. 656).

Como afirmam Correa e Petchesky (1996, p. 159), para que as decisões reprodutivas possam ser exercidas efetivamente, assim como a autonomia das mulheres para fazerem escolhas nesse campo, há que existir condições concretas. Isso remete às condições de trabalho e renda, moradia, educação, 
transporte, educação infantil, escolas em período integral, serviços de saúde humanizados e bem equipados, entre outros. Também é essencial a construção de relações afetivas compartilhadas sem violência de qualquer tipo. Para isso, requer-se a responsabilidade de Estados e instituições mediadoras, pressupondo uma ação pública para garantir que os direitos sejam exercidos por todos e todas.

Cabe aqui um destaque ao debate sobre direitos. Para Telles (1998) é necessário colocar os direitos sob a ótica daqueles sujeitos que os pronunciam. Isso significa considerar os direitos não apenas como meras concessões de Estado capitalista para as classes subalternas, mas como espaço de disputa e de construção também por aqueles que os demandam. O debate sobre direitos, apesar de não proporcionar automaticamente a emancipação humana e não romper com a ordem vigente, abre possibilidades para os grupos oprimidos.

É nesse aspecto que a luta pelos direitos é importante: apesar de, via direitos, não ser possível alcançar o fim das desigualdades, ou aquilo que Marx (2010) define como emancipação humana, ela permite que a ordem social seja questionada, que sujeitos desprovidos de poder quebrem o silêncio e a naturalização da sua condição subalterna e busquem outras possibilidades. A partir do questionamento e do movimento dos grupos oprimidos, a busca por novas vozes, novas perspectivas, outros pontos de vista, de resistência, a busca pelo compartilhamento do poder pode se tornar uma possibilidade.

É nesse sentido que a luta das mulheres pelos seus direitos se enquadra. Quando as feministas lutam pela legalização do aborto, não estão apenas colocando o aborto em questão, mas um sistema que domina e explora mulheres, que instrumentaliza a sua capacidade biológica e as reduz ao único destino da maternidade como sua função social.

O processo de construção dos direitos reprodutivos e sexuais, segundo Ávila (2003), está integrado ao processo mais amplo de construção da democracia, uma vez que o controle do corpo e da sexualidade são centrais para a dominação patriarcal. 


\section{A questão do aborto no Brasil}

No final da década de 1970 o discurso era pelos direitos humanos das mulheres e estava alinhado à premissa "nosso corpo nos pertence". Conforme o relato de Eleonora M. Oliveira,

As feministas brasileiras, nosotras, ex-exiladas, ex-presas políticas, viajantes, trouxeram, no final da década de 1970 e no início da década de 1980, essa questão dos direitos humanos das mulheres com muita força e com muita radicalidade para as mobilizações. Radicalidade que está associada à luta pelo direito ao aborto, na medida em que essa questão se relaciona à noção mais forte, mais reacionária, mais conservadora da maternidade compulsória, que é base da moral judaico-cristã. (Oliveira, 2005, p. 132)

A autora relata que a luta pelo direito ao aborto "foi uma luta muito solitária das mulheres feministas" (2005, p. 133). Isso porque as mulheres estavam sós tanto enquanto construíam uma rede de solidariedade entre as que fizeram aborto, como também estavam sós em seus próprios abortos. Os homens, quando muito, apenas e simplesmente "davam o dinheiro". Além disso, Oliveira (2005) comenta sobre a solidão política sofrida pelas feministas que lutavam pelo direito ao aborto nos diferentes espaços que ocupavam.

Com a reabertura política no Brasil, as pautas do movimento feminista ganharam força novamente e, dentre elas, a questão dos direitos reprodutivos das mulheres. Nesse contexto, na década de 1980 uma grande quantidade de mulheres saiu às ruas pela legalização e descriminalização do aborto, bem como pelo direito de escolha.

Nesse sentido, Valdívia (1998) e Faria e Lopes (2016) informam que a luta das mulheres e organizações/instituições feministas foi essencial no contexto da constituinte. Na época, a participação popular na construção da Constituição brasileira era possibilitada por meio de emendas populares. Movimentos de mulheres feministas trabalharam intensamente para a inserção 
de suas demandas por meio dessas emendas. Uma dessas demandas era a descriminalização do aborto.

As feministas lutavam para que a Constituição Federal defendesse o direito à vida "desde o nascimento", a fim de buscar avanços na legislação sobre aborto. Porém, o forte lobby da Igreja Católica e a massiva presença de deputados evangélicos tentavam impor a defesa da vida "desde a concepção" - o que impossibilitaria inclusive os permissivos de aborto nos casos citados pelo Código Penal de 1940. A recusa do termo "desde a concepção" para se referir à vida foi uma conquista do movimento de mulheres feministas. Como resultado desse embate, a Constituição brasileira afirma o direito à vida, sem determinar quando esta começa — dando brecha para os dois lados.

Todavia, na data em que escrevemos este texto, há novamente a tentativa de incluir esse conceito na Constituição Federal. Dentre vários projetos que preveem retrocessos nos direitos das mulheres, a Proposta de Emenda Constitucional (PEC) n. 181 é uma das mais agressivas e sorrateiras. Conhecida como PEC Cavalo de Troia, a proposta inicialmente tinha como objetivo prolongar a licença-maternidade de mães de bebês prematuros. Após diversas modificações, consta no texto a alteração da Constituição para a garantia da "inviolabilidade do direito à vida desde a concepção", ${ }^{2}$ novamente com o nítido intuito de impossibilitar o direito ao aborto.

$\mathrm{Na}$ legislação brasileira, a partir do Código Penal de 1940, o aborto é crime tipificado segundo o título I, dos crimes contra a pessoa, e do capítulo I, dos crimes contra a vida. Podemos perceber no documento a diferença entre aborto e infanticídio: é considerado infanticídio "matar, sob a influência do estado puerperal, o próprio filho, durante o parto ou logo após" (art. 123 do Código Penal). É considerado aborto quando a situação consiste em "provocar aborto em si mesma ou consentir que outrem lho

2. O texto completo com as alterações da relatoria da PEC pode ser observado em: $<$ http://www.camara. gov.br/proposicoesWeb/prop_mostrarintegra;jsessionid=54A20260D836F4E17061509229493620.proposicoesWebExterno1?codteor=1586817\&filename=Parecer-PEC18115-16-08-2017>. 
provoque" (art. 124 do Código Penal). O Código atenua a pena àqueles que realizam o procedimento com o consentimento da mulher, e, por outro lado, aumenta a pena caso a gestante sofra lesões corporais graves ou chegue a óbito.

O abortamento no Brasil, segundo os incisos I e II do artigo 128 do Código Penal, é permitido em casos de gravidez decorrente de estupro (abortamento sentimental), em casos de risco de vida para a gestante (abortamento necessário). A Justiça também pode conceder autorizações específicas quando as gestações possuem anomalias fetais incompatíveis com a vida extrauterina, como no caso da anencefalia.

Em 1999, o governo federal lança a primeira Norma Técnica para Prevenção e Tratamento dos Agravos Resultantes da Violência Sexual Contra Mulheres e Adolescentes com intuito de estabelecer normas gerais para o atendimento dessas demandas. A norma técnica de 1999 é resultado da pressão de diversas organizações feministas e previa:

Apoio laboratorial para diagnóstico de doenças sexualmente transmissíveis (DSTs) e Aids; prevenção profilática de DST; garantia de atendimento psicológico; coleta e guarda de material para futura identificação do agressor por exame de DNA; administração de anticoncepção de emergência (até 72 horas da agressão); interrupção da gravidez até vinte semanas de idade gestacional; acompanhamento pré-natal, quando a mulher decidir pela não interrupção. (Talib, 2005, p. 21)

Em 2005, o governo federal lança, em resposta à pressão de diversas organizações feministas, uma nova versão da Norma Técnica para Prevenção e Tratamento dos Agravos Resultantes da Violência Sexual Contra Mulheres e Adolescentes e também lança a inédita Norma Técnica de Atenção Humanizada ao Abortamento. A primeira trata do atendimento às vítimas de violência sexual e inclui questões como apoio psicossocial, contracepção de emergência, doenças e infecções sexualmente transmissíveis e também $\mathrm{o}$ atendimento nos casos de gravidez resultante de estupro. $\mathrm{O}$ documento 
discorre ainda sobre a organização do serviço, desde a estrutura física e equipamentos até a capacitação e sensibilização dos recursos humanos, além do registro de dados.

As referidas normas técnicas reforçam conteúdos já presentes no Código Penal para normatizar os atendimentos tanto no caso das vítimas de violência sexual quanto nas situações de abortamento em geral. Um ponto trazido nas normas faz referência à dispensa de Boletim de Ocorrência para a realização do abortamento em casos de gravidez resultante de estupro. Segundo o Código Penal brasileiro, e conforme reforçado na norma técnica, a única coisa a ser requisitada nesses casos é uma autorização por escrito da mulher ou da(o) responsável para a realização dos procedimentos. Da mesma forma, a presunção da veracidade no relato das mulheres sobre a violência sexual sofrida é enfatizada pelo documento.

A Norma Técnica de Atenção Humanizada ao Abortamento, lançada em 2005 e atualizada em 2008, traz importantes avanços no que se refere ao acolhimento e atendimento de mulheres em situação de abortamento. $\mathrm{O}$ documento discorre sobre o dever dos profissionais da saúde no atendimento às mulheres tanto em caso de abortamento espontâneo quanto autoprovocado. A norma também discorre sobre a importância do respeito ao sigilo profissional sobre as situações de abortamento, bem como o tratamento humanizado que deve ser conferido às mulheres independentemente da situação que decorreu no aborto.

As normas apontam que é dever do Estado garantir a presença nos serviços de atendimento de médicos e outros profissionais que não tenham objeção de consciência ${ }^{3}$ para realização do procedimento. Da mesma forma, afirma que "caso a mulher venha sofrer prejuízo de ordem moral, física ou psíquica, em decorrência da omissão, poderá recorrer à responsabilização pessoal e/ou institucional" (Brasil, 2005, p. 44).

3. A legislação brasileira assegura que profissionais contrários ao aborto possam recusar-se à realização do procedimento, caso não seja uma urgência e haja outros profissionais capacitados para a realização deste. Ao atendimento às mulheres com complicações decorrentes de abortamento não cabe objeção de consciência dos profissionais, sendo seu dever atender a esses casos. 
Os documentos citados deixam evidente a necessidade de uma equipe multidisciplinar para isso e afirma que todos os profissionais da saúde têm responsabilidade no atendimento.

É desejável que a equipe de saúde seja composta por médicos(as), psicólogos(as), enfermeiros(as) e assistentes sociais. Entretanto, a falta de um ou mais profissionais na equipe - com exceção do médico(a) - não inviabiliza o atendimento. Ainda que cada um desses profissionais cumpra papel específico no atendimento à mulher, todos devem estar sensibilizados para as questões de violência contra a mulher e violência de gênero, e capacitados para acolher e oferecer suporte às suas principais demandas. (Brasil, 2005, p. 11)

Conforme vimos anteriormente, apesar de constituir direito das mulheres desde o Código Penal de 1940, apenas em 1990 um hospital público ofereceu, pela primeira vez, o serviço de abortamento legal. Trata-se do Hospital do Jabaquara, em São Paulo. Segundo Villela e Lago:

Em 1996, ocorreu a recomposição da Comissão Intersetorial da Saúde da Mulher (Cismu), instância assessora do Conselho Nacional da Saúde que ao ser rearticulada passa a contar com uma forte presença de feministas e com a representação da Febrasgo [Rede Nacional Feminista de Saúde e Direitos Reprodutivos e Sexuais e a Federação Brasileira de Ginecologia e Obstetrícia]. Por meio de uma negociação interna entre a Cismu e representantes do Ministério da Saúde, foi proposta a elaboração de uma norma técnica para a implementação de serviços de atendimento à violência sexual que incluísse o aborto. Após discussão no Conselho Nacional de Saúde, a proposta foi aprovada e encaminhada à Área Técnica de Saúde da Mulher, para ser implementada. (Villela e Lago, 2007, p. 473)

Não obstante a legislação e as normas, relatos colhidos por nós junto a assistentes sociais que atuam nesses serviços mostram várias dificuldades no atendimento ao abortamento previsto pela lei. Segundo os relatos, mesmo quando a equipe do Serviço Social é constituída por profissionais 
voltados para a perspectiva de reconhecimento do direito, o setor não atende sozinho, contando com outros profissionais para esse atendimento. Assim, o enfrentamento da equipe de Serviço Social é essencial para confrontar práticas profissionais preconceituosas, culpabilizadoras e a negação dos direitos das mulheres.

Um dos exemplos disso é a garantia do acesso ao abortamento previsto pela lei sem a realização do boletim de ocorrência. Segundo uma das entrevistadas, o único médico da instituição que aceitava realizar o aborto, requisitava o boletim de ocorrência para dar sequência ao procedimento. $\mathrm{O}$ embate das assistentes sociais possibilitou a garantia do direito ao abortamento, conforme dispõe as normas técnicas de 2005 e 2008.

Terminamos este tópico lembrando que foi uma assistente social do Hospital do Jabaquara em São Paulo que liderou a luta para implantação de um dos primeiros serviços de abortamento legal no Brasil, o que nos aponta para a importância do Serviço Social nesse contexto.

\section{Serviç̧o Social, direitos reprodutivos e aborto}

A partir do desenvolvimento de uma concepção crítica do Serviço Social, cunhou-se um novo projeto profissional, que, segundo Netto (2001), tem em seu núcleo o reconhecimento da liberdade como valor central - a liberdade historicamente concebida, que permite a escolha entre alternativas reais, concretas. Esse projeto profissional está alinhado a um projeto societário livre de opressões de classe, raça/etnia e gênero.

O Código de Ética do Serviço Social (Brasil, 2012), de 1993, revisado e atualizado em 2011, traz como um dos princípios fundamentais o reconhecimento da liberdade como valor central, bem como das demandas políticas relativas a ela, como a autonomia, a emancipação e a plena expansão dos indivíduos sociais. A discussão feminista sobre o aborto tem como eixo norteador a autonomia das mulheres, o que nos aponta novamente para aproximação entre essa questão e o Serviço Social. 
A defesa intransigente dos direitos humanos e a recusa do arbítrio e do autoritarismo aparecem no segundo item dos princípios fundamentais do Código, seguidos da ampliação da cidadania e defesa do aprofundamento da democracia na socialização da participação política e da riqueza socialmente produzida. O item n. 5 afirma o posicionamento em favor da equidade e da justiça social, assegurando acesso universal a bens e políticas sociais, além da sua gestão democrática. $\mathrm{O}$ empenho na eliminação de todas as formas de preconceito aparece no item 6 . O referido código também traz a escolha por um projeto profissional em busca de uma sociedade sem dominação, seja ela de classe, etnia ou gênero (Brasil, 2012).

O Conselho Nacional de Serviço Social, CFESS, tem se posicionado frente aos direitos reprodutivos. Em 2009, o CFESS Manifesta de 28 de setembro ${ }^{4}$ traz um panorama sobre a questão do aborto, colocando-a como uma questão de saúde pública e direito das mulheres. O referido documento relata que no $38^{\circ}$ Encontro Nacional CFESS-Cress, os assistentes sociais presentes

Reafirmaram seus valores e princípios, comprometidos com a emancipação humana e a construção de uma nova ordem societária, livre de toda forma de exploração e opressão, e deliberaram o posicionamento e o engajamento nas lutas pela descriminalização do aborto, e a realização de debates em todo o Brasil sobre a legalização do aborto como mecanismo de ampliar e democratizar as discussões no âmbito da categoria, para retirada de posicionamento do Conjunto CFESS/Cress em setembro/2010. (CFESS, 2009)

No mesmo documento, é endossado o compromisso ético-político com a defesa dos direitos sexuais e reprodutivos das mulheres e o apoio ao movimento feminista nessa luta, uma vez que "o aborto inseguro é uma gravíssima questão de saúde pública e que as mulheres constituem seres éticos capazes de fazer escolhas de forma consciente e responsável" (CFESS, 2009).

4. O dia 28 de setembro foi escolhido, pelos movimentos feministas presentes no V Encontro Feminista Latino-Americano e do Caribe, como o Dia Latino-Americano e Caribenho de Luta pela Descriminalização e Legalização do Aborto. 
Assim, conforme proposto em 2009, no ano seguinte, em setembro de 2010, por ocasião do $39^{\circ}$ Encontro Nacional CFESS-Cress, colocou-se o assunto em pauta novamente. Dessa vez, os assistentes sociais representantes de todas as regiões do país deliberaram coletivamente pelo apoio à legalização do aborto. O debate foi feito no eixo Ética e Direitos Humanos do evento, no qual decidiu-se coletivamente pelo posicionamento. Antes, o tema já havia sido debatido em reuniões e assembleias nas regionais do Conselho. ${ }^{5}$

Em 2011, também no dia 28 de setembro, um CFESS Manifesta foi lançado em apoio à legalização do aborto. As exigências e compromissos de 2009 foram novamente endossados, argumentando a defesa da legalização do aborto como questão de saúde pública, uma vez que é a terceira causa de morte materna e penaliza ainda mais as mulheres pobres e negras que não têm condições de acesso aos abortos clandestinos minimamente seguros. Além disso, também relata as ações deliberadas no $40^{\circ}$ Encontro Nacional CFESS-Cress para a luta pela legalização do aborto.

É importante ressaltar que o CFESS também se manifestou, em 2015, em repúdio ao Projeto de Lei n. 5069/2013, de autoria de Eduardo Cunha. Na nota de repúdio, o Conselho informa que o projeto "prevê a criminalização do anúncio de métodos abortivos e da prestação de auxílio ao aborto, principalmente por parte de profissionais de saúde", e informa também o parecer do relator (Evandro Gussi, PV/SP) um "atentado ao aparato legal já existente sobre o tema, um retrocesso às lutas históricas de movimentos feministas e, principalmente, um ataque à saúde de milhares de mulheres no Brasil" (Idem). A nota de repúdio finaliza endossando o posicionamento contrário ao referido projeto de lei e afirmando a luta histórica da categoria pela legalização do aborto.

Outro CFESS Manifesta foi lançado em 28 de setembro de 2016 em apoio ao Dia Latino-Americano e Caribenho de Luta pela Descriminalização Legalização do Aborto. Trazendo considerações sobre o aborto e o trabalho

5. Conforme informações do site do Conselho Federal de Serviço Social, disponível em: <http://www. cfess.org.br/visualizar/noticia/cod/471>. Acesso em: 15 mar. 2018. 
dos assistentes sociais, o documento de 2016 traz novamente a questão da saúde pública, mas também argumenta, norteado pela autonomia das mulheres. O slogan feminista "nosso corpo nos pertence" é trazido para o debate.

O CFESS Manifesta de 28 de setembro de 2016 vai questionar os valores conservadores e expressar a necessidade de combatê-los na prática profissional, bem como de pensar o assunto de maneira crítica, conforme podemos observar abaixo:

No campo da atuação profissional, apesar do avanço do debate que se expressa em deliberações e ações do conjunto CFESS-Cress e do posicionamento político da categoria nos instrumentos normativos que compõem o projeto ético-político profissional, podemos identificar ações profissionais que negam os direitos das mulheres, no sentido de ampliação de acesso a informações e de posicionamentos conservadores e questionadores frente à situação de decisão das mulheres sobre o aborto. (CFESS, 2016)

Para fazer essa defesa, os princípios éticos e políticos do Serviço Social são ressaltados: a defesa intransigente dos direitos, a busca por uma nova ordem societária sem opressão de classe, gênero e raça/etnia, o enfrentamento das desigualdades. Categorias como emancipação humana e autonomia também são utilizadas no documento para fundamentar o debate, além dos posicionamentos dos movimentos feministas sobre esse tema.

Embora o debate esteja presente nos órgãos de defesa da categoria, não está necessariamente presente no conjunto da categoria. Em dados coletados dados junto a assistentes sociais em $2017^{6}$ por meio de questionários, pudemos verificar que das cem entrevistadas, $46 \%$ afirmaram que a discussão sobre aborto não esteve presente na sua formação acadêmica/profissional; $28 \%$ afirmaram que essa discussão esteve parcialmente presente na formação acadêmica/profissional, $10 \%$ não se recordam e $1 \%$ não sabe do que se trata. Apenas $15 \%$ das assistentes sociais responderam que a discussão sobre

6. 4 Dados coletados para pesquisa em andamento sobre aborto e Serviço Social, no programa de Pós-Graduação Política Social e Serviço Social da Universidade Estadual de Londrina. 
direitos reprodutivos esteve presente na formação acadêmica/profissional. Em entrevistas presenciais, algumas assistentes sociais pontuaram que tiveram contato com o debate sobre aborto e/ou direitos reprodutivos devido ao surgimento dessas demandas no cotidiano profissional.

Segundo as entrevistadas, o debate sobre aborto é levado na categoria profissional apenas por grupos pequenos que têm uma perspectiva feminista e/ou já estão inseridos na luta pela legalização do aborto. Os relatos apontam para a ausência desse debate de forma coletiva entre as assistentes sociais.

O posicionamento do CFESS pela legalização do aborto é conhecido por quase todas as assistentes sociais entrevistadas. Entretanto, a maior parte delas declara não ter lido nenhum documento que detalhe e justifique esse posicionamento.

Como nos traz Bonfim, "escolhas éticas só são possíveis a partir da relação dialética entre necessidade e liberdade" (2015, p. 202), o que reforça a necessidade de reconhecer as condições objetivas e subjetivas de trabalho desses profissionais, bem como do contexto em que estão inseridos.

\section{Considerações finais}

A luta das mulheres pela liberdade sexual e reprodutiva, bem como pela legalização do aborto, conforme percebemos, sempre foi pauta do movimento feminista. Afirmando que "o pessoal é político", o movimento feminista pôde colocar em debate várias questões que antes eram deixadas de lado, pois “não eram de interesse público". Conforme nos traz Ávila, essa discussão se torna essencial, uma vez que "as interdições legais sobre a vida amorosa, sexual e reprodutiva se transformaram, de fato, em mecanismos insuportáveis na vida cotidiana, pois são instrumentos de dominação, de repressão e de violência" (2005, p. 18).

A questão do aborto no Brasil exige não apenas a mudança na lei, mas também a adaptação das políticas sociais e as mudanças nos padrões estabelecidos culturalmente e que respaldam as práticas sociais. Seguindo esse 
caminho, a questão do reconhecimento do direito ao aborto não deve ser encarada apenas com o estabelecimento do direito em lei, já que as práticas sociais que atravessam essa situação também impossibilitam ou precarizam o acesso a esse direito, assim como as políticas sociais não são suficientes ou devidamente preparadas para o atendimento dessas demandas. Prevalece ainda a imagem da mulher que abortou como criminosa e assassina; a mulher que vivencia a sexualidade como desfrutável ou sem valor; a maternidade como missão e dever da mulher.

No que tange ao Serviço Social, mesmo com as diversas manifestações do CFESS e do posicionamento oficial em relação ao aborto, não é possível afirmar que, no cotidiano de trabalho, as assistentes sociais traduzam essa direção em sua prática profissional. Assim como não é possível afirmar que conheçam ou concordem com o posicionamento do CFESS.

Ainda é forte a presença de valores religiosos conservadores na prática profissional, mesmo depois do movimento de reconceituação e da construção do Projeto Ético-Político do Serviço Social, o que nos mostra um tensionamento entre a moral conservadora à brasileira e o Projeto Ético-Político do Serviço Social quando o assunto é aborto. Essa moral não está presente apenas na formação dessa profissão, mas em toda a sociedade brasileira (Bonfim, 2015).

Conforme pudemos ver, o enfrentamento político dos assistentes sociais é essencial para a garantia dos direitos já conquistados, inclusive no que se refere ao aborto. Se visto enquanto um direito humano das mulheres, a negação dos seus direitos reprodutivos é considerada uma violação séria, e, portanto, de interesse do assistente social.

O contato do assistente social com situações de vulnerabilidade e negação de direitos traz, ao mesmo tempo, responsabilidade e possibilidades. Uma vez munido dessas informações, como colocado por Iamamoto (2015), o assistente social pode agir no atendimento e na socialização das informações, a fim de denunciar essa realidade, sendo de profunda importância para a garantia e conquista de direitos. Tomam também contato diariamente com o sofrimento de mulheres pobres, de maioria negra, com pouca perspectiva 
de autonomia, que sofrem violências de todos os tipos, inclusive a violação de direitos reprodutivos.

Recebido em 7/1/18 - Aprovado em 26/2/18

\section{Referências bibliográficas}

ÁVILA, M. B. Direitos sexuais e reprodutivos: desafios para a política de saúde. Cadernos de Saúde Pública, Rio de Janeiro, v. 19, sup. 2. 2003.

ÁVILA, M. B. Liberdade e legalidade: uma relação dialética. In: ÁVILA, M. B.; PORTELLA, A. P.; FERREIRA, V. (Orgs.). Novas legalidades e democratização da vida social: família, sexualidade e aborto. Rio de Janeiro: Garamond, 2005.

BONFIM, P. Conservadorismo moral e Serviço Social: a particularidade da formação moral brasileira e a sua influência no cotidiano de trabalho dos assistentes sociais. Rio de Janeiro: Lumen Juris, 2015.

BRASIL, Ministério da Saúde. Secretaria de Atenção à Saúde. Departamento de Ações Programáticas Estratégicas. Área Técnica de Saúde da Mulher. Prevenção e tratamento dos agravos resultantes da violência sexual contra mulheres e adolescentes: norma técnica. 2. ed. atual. e ampl. Brasília: Ministério da Saúde, 2005.

BRASIL. Código de ética do/a assistente social. Lei n. 8.662/93 de regulamentação da profissão. 10. ed. rev. e atual. Brasília: Conselho Federal de Serviço Social, 2012.

. Código penal. Disponível em: <http://www.planalto.gov.br/ccivil_03/ decreto-lei/Del2848compilado.htm> Acesso em: 20 maio 2017.

. Pela descriminalização e legalização do aborto. CFESS Manifesta, Brasília, 28 set. 2009. Disponível em: <www.cfess.org.br>. Acesso em: 5 maio 2017.

CONSELHO FEDERAL DE SERVIÇO SOCIAL. Dia Latino-Americano e Caribenho de Luta pela Descriminalização e Legalização do Aborto. CFESS Manifesta, Brasília, 28 set. 2011. Disponível em: <www.cfess.org.br>. Acesso em: 5 maio 2017. 
CONSELHO FEDERAL DE SERVIÇO SOCIAL. Dia Latino-Americano e Caribenho de Luta pela Descriminalização e Legalização do Aborto. CFESS Manifesta, Brasília 28 set. 2016. Disponível em: <www.cfess.org.br>. Acesso em: 5 maio 2017.

. Nota de repúdio do Conselho Federal de Serviço Social ao PL n. 5.069/2013. Brasília: CFESS, 2015. Disponível em: <www.cfess.org.br>. Acesso em: 5 maio 2017. CORREA, S.; PETCHESKY, R. Direitos sexuais e reprodutivos: uma perspectiva feminista. Physis, Rio de Janeiro, v. 6 (1/2), p. 147-177, 1996.

DAVIS, A. Mulheres, raça e classe. São Paulo: Boitempo, 2016.

DINIZ, D.; MEDEIROS, M.; MADEIRO, A. Pesquisa Nacional de Aborto 2016. Ciência e Saúde Coletiva, Rio de Janeiro, v. 22, n. 2, p. 653-660, 2017.

FARIA, N.; LOPES, B. As lutas pelo direito ao aborto, ontem e hoje. In: LOPES, B.; MARTINS, J.; MORENO, T. (Orgs.). Somos todas clandestinas: relatos sobre aborto, autonomia e política. São Paulo: SOF, 2016.

IAMAMOTO, M. V. Serviço Social em tempo de capital fetiche: capital financeiro, trabalho e questão social. 9. ed. São Paulo: Cortez, 2015.

KERGOAT, D. Dinâmica e consubstancialidade das relações sociais. Novos Estudos Cebrap, São Paulo, n. 86, p. 93-103, 2010.

MARX, K. Sobre a questão judaica. São Paulo: Boitempo, 2010.

MESQUITA, R. F. Aborto inseguro. In: ROTANIA, A. Bioética: vida e morte femininas. Rio de Janeiro: Rede Nacional Feminista de Saúde e Direitos Reprodutivos, 2000.

NAÇÕES UNIDAS Report of the International Conference of Population and Development, Cairo. Nova York: Nações Unidas (n. 95 XIII. 18), 1995.

. Report of the Fourth World Conference of Women, Beijing. Nova York: Nações Unidas (n. 96. IV. 13), 1996.

NETTO, J. P. A construção do Projeto Ético-Político do Serviço Social. Serviço Social \& Saúde, Brasília, 2001.

OLIVEIRA, E. M. Os sujeitos da luta pela legalização do aborto. In: ÁVILA, M. B.; PORTELLA, A. P.; FERREIRA, V. (Orgs.). Novas legalidades e democratização da vida social: família, sexualidade e aborto. Rio de Janeiro: Garamond, 2005. 
SAFFIOTI, H. I. B. Gênero, patriarcado, violência. 1. ed. São Paulo: Fundação Perseu Abramo, 2004.

TALIB, R. A. Dossiê: serviços de aborto legal em hospitais públicos brasileiros (19892004). São Paulo: Católicas pelo Direito de Decidir, 2005.

TELLES, V. Direitos sociais: afinal, do que se trata? Revista USP, São Paulo n. 37, 1998. Disponível em: <http://www.revistas.usp.br/revusp/article/view/27023/28797>. Acesso em: 10 ago. 2016.

VALDÍVIA, V. B. Silêncios públicos, mortes privadas: a regulamentação jurídica do aborto na América Latina e Caribe. São Paulo: Comitê Latino-Americano e do Caribe para Defesa dos Direitos da Mulher (Cladem), 1998.

VENTURA, M. Direitos reprodutivos no Brasil. 3. ed. Brasília: UNFPA, 2009.

VILlELA, W. V.; LAGO, T. Conquistas e desafios no atendimento das mulheres que sofreram violência sexual. Cad. Saúde Pública, Rio de Janeiro, v. 23, n. 2, 2007. Disponível em: <http:/www.scielo.br/scielo.php?script=sci_arttext\&pid=S0102311X2007000200025>. Acesso em: 10 mar 2017. 